\title{
Overall Circuit Design and Simulation of UHVDC Current Transformer Calibration Current Source
}

\author{
Hao Pan ${ }^{1}$, Ke Wang ${ }^{1, *}$, Xuejiao Chen ${ }^{2}$ and Fangrong Zhou ${ }^{1}$ \\ ${ }^{1}$ Electrical Research Institute of Yunnan Electric Power Research Institute (Group) Co., Ltd., Kunming, 650051, China \\ ${ }^{2}$ College of Electrical Engineering, Southwest Jiaotong University, Chengdu 611756, China \\ ${ }^{*}$ Corresponding author
}

\begin{abstract}
In order to study the modular, easy-to-assemble DC calibration current source for DC current transformer. In this paper, the technical indicators and design requirements are analyzed theoretically. Based on the structural design of various technical solutions and the applicable power range, the theoretical overall design and simulation of the circuit topology of high-current DC current generating devices are performed. By comparing and analyzing the simulation results, the circuit topology of current source is determined.
\end{abstract}

Keywords-DC current transformer; DC current source; Circuit design; PSIM simulation

\section{INTRODUCTION}

With the development of the electric power industry, the ultra-high voltage direct current (UHVDC) Transmission is increasing day by day [1-3]. The DC current transformer is an important primary equipment of the UHVDC transmission system [4-5]. It is used to provide instantaneous and accurate measurement information for system control and protection. Its operational reliability and measurement accuracy are directly related to the safety and normal operation of the UHVDC transmission system. In the engineering, the DC current transformer is often calibrated by a DC transformer calibrator. However, the DC generator of the core equipment of the DC transformer calibrator is relatively large, causing the calibrator of the DC transformer to be inconvenient to be calibrated at the engineering site [6-7]. Therefore, it is urgent to study a modular, easy-to-assemble DC current source for calibration.

In this paper, the technical indicators and design requirements are analyzed theoretically. Based on the structural design of various technical solutions and the applicable power range, the theoretical overall design and simulation of the circuit topology of high-current DC current generating devices are performed. By comparing and analyzing the simulation results, the circuit topology of current source is determined.

\section{TECHNICAL REQUIREMENTS AND PARAMETER ANALYSIS}

In this paper, a current generator for accuracy verification of DC current transformers for $\pm 800 \mathrm{kV}$ UHVDC converter stations is designed.

\section{A. Current Amplitude Analysis}

At present, the maximum rated current of the current transformer used in the $\pm 800 \mathrm{kV}$ UHVDC converter station is $4500 \mathrm{~A}$, and the upper limit of the measurement can best be measured to $120 \%$ of the rated current range. Therefore, the DC power supply is required to output a minimum of 5400A.

\section{B. Load Analysis}

The resistance of the active photoelectric DC current transformer mainly includes the shunt resistance, the lead resistance and the contact resistance. The zero-flux current transformer is mainly the lead resistance and the contact resistance. Therefore, whether it is active photoelectric DC transformer or zero-flux current transformer. The sum of the dc resistance and the lead resistance of a dc transformer generally does not exceed approximately $200 \mu \Omega$, so the required power for an output current of 5400A is as follows:

$$
\begin{aligned}
P & =I^{2} \times R=5400^{2} \times\left(200 \times 10^{-6}\right) \\
& =5832 \mathrm{~W}
\end{aligned}
$$

The maximum output voltage is as follows:

$$
\begin{aligned}
U & =I \times R=5400 \times\left(200 \times 10^{-6}\right) \\
& =1.08 \mathrm{~V}
\end{aligned}
$$

Taking into account the power consumed by the current measurement resistor, the maximum output power is $9 \mathrm{~kW}$.

\section{A VARIETy OF Circuit Design}

The DC stabilized current supply is a low-voltage, highcurrent version. Low-voltage high-current power supplies have a variety of technical principles, but the application of various technical principles has different applicability. Therefore, it needs to choose the most suitable solution for product development.

\section{A. Technical Solution One}

The technical solution is shown in Fig. 1. 


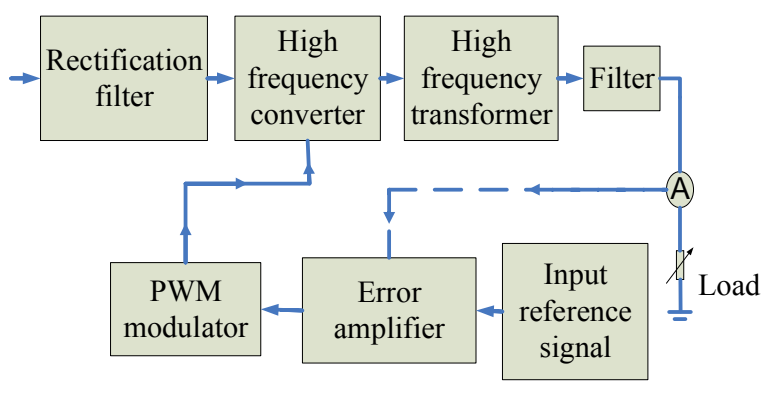

FIGURE I. TECHNICAL PLAN ONE

The basic steps are as follows:

1) Rectify and filter $380 \mathrm{~V}$ three-phase circuit or $220 \mathrm{~V}$ single-phase circuit to obtain DC voltage;

2) The PWM modulator controls the on/off of the high frequency converter so that the DC voltage obtained in step 1) is converted into a high frequency voltage signal;

3) The high-frequency AC signal obtained in step 2) passes through a high-frequency transformer and outputs a low-voltage large current.

4) The error amplifier is controlled by sampling the lowvoltage and high-current, and then the PWM modulation signal is controlled so as to achieve negative feedback, thereby obtaining a stable current output.

The essence of this technical plan is to adjust the output voltage in real time according to the load current. The advantage is that the high-frequency transformer is used as the core of energy conversion, and its volume is relatively small and it is easy to transport. The disadvantage is that the power electronic device must be able to withstand a large load current, on the one hand the cost of the device is high, and on the other hand the life of the device is greatly affected by the load current.

\section{B. Technical Solution Two}

The essence of the technical solution is to regard the device of technical solution one as a current module, and the maximum output current of each module can be fixedly selected as $600 \mathrm{~A}$, and 9 modules can be connected in parallel to realize the output of a maximum current of 5400A.

The current control method of this scheme includes two kinds: 1) each module controls separately, each current module needs to dispose the high-accuracy current acquisition module; 2) Through the load current unified control, this method needs to consider the technical problem of current circulation.

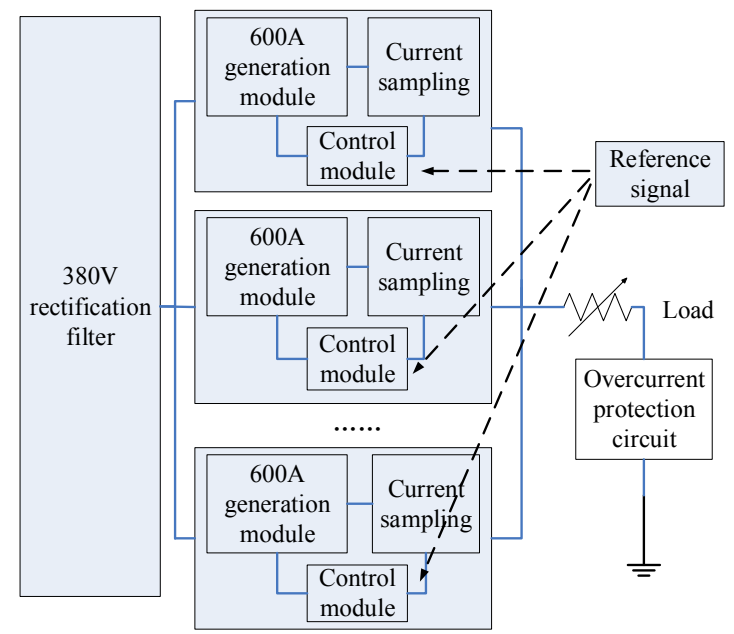

FIGURE II. INDIVIDUALLY CONTROLLED CURRENT OUTPUT SCHEME

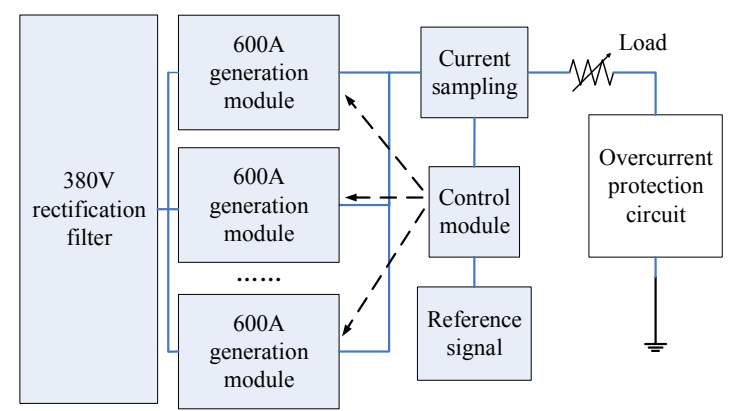

FIGURE III. UNIFIED CONTROL CURRENT OUTPUT SCHEME

\section{SimULATION COMPARISON AND ANALYSIS OF VARIOUS SOLUTIONS}

Using PSIM professional simulation software to analyze the result of the current source, the following describes the two types of operating conditions of the separate current source module and multiple current source modules in parallel.

\section{A. Simulation of Individual Current Source Module}

Fig. 4 shows the simulation circuit diagram of the separate current source module. Since the output value of the $380 \mathrm{~V}$ rectifier circuit is $514 \mathrm{~V}$, for convenience, the rectifier current is ignored and the voltage of $514 \mathrm{~V}$ is directly input in the simulation. The maximum output current of the current source module is $600 \mathrm{~A}$. RL is the load resistance, which is the sum of the DC resistance of the current transformer and the lead. In the simulation, the load resistance RL is equal to $200 \mu \Omega$. Due to the use of automatic control technology, in the case of guaranteed power, the actual load is independent of the output current but is related to the voltage across the load. R3 is the current sampling resistor, which can use the instrument-level sampling resistance. Under the rated condition, the current sampling resistance output is $75 \mathrm{mV}$. Since the rated output is $600 \mathrm{~A}$, the selected resistance value is equal to $125 \mu \Omega$. The PWM control signal is $20 \mathrm{kHz}$, so the high frequency transformer selects the center frequency of $20 \mathrm{kHz}$. VDC2 is the reference signal and corresponds to the current value. In the 
actual system, the input reference signal source is designed to replace it.

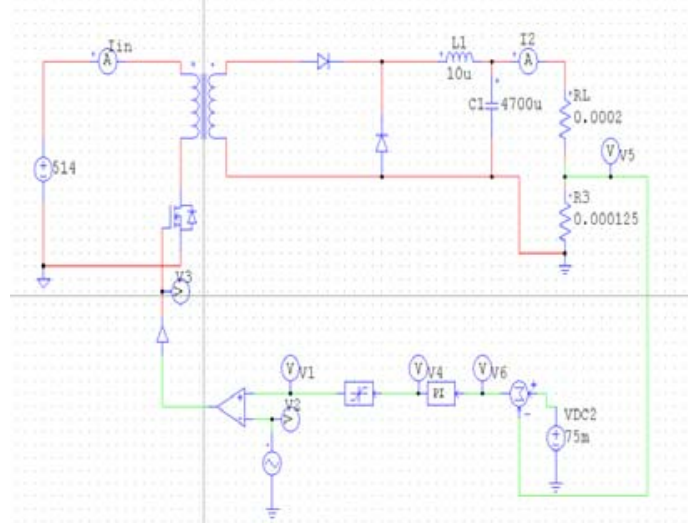

FIGURE IV. SIMULATION CIRCUIT DIAGRAM OF THE SEPARATE CURRENT SOURCE MODULE

The current output simulation results are shown in Fig. 5. According to the simulation results in Fig. 5, the waveform is stable at $600 \mathrm{~A}$ at rated load, and the response time of the output current from $0 \mathrm{~A}$ to $600 \mathrm{~A}$ is about $0.01 \mathrm{~s}$, so the power supply has a fast response speed.

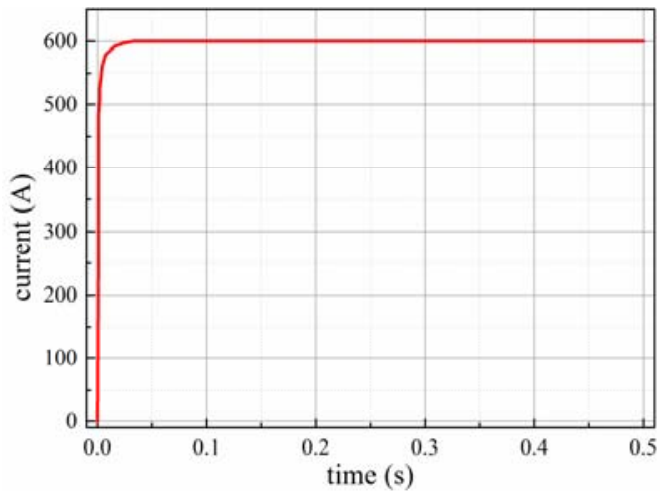

FIGURE V. INDIVIDUAL CURRENT SOURCE MODULE CURRENT OUTPUT

Fig. 6 and Fig. 7 show the waveforms of the PWM pulse signal (V3) in the starting stage and the stable stage, respectively.

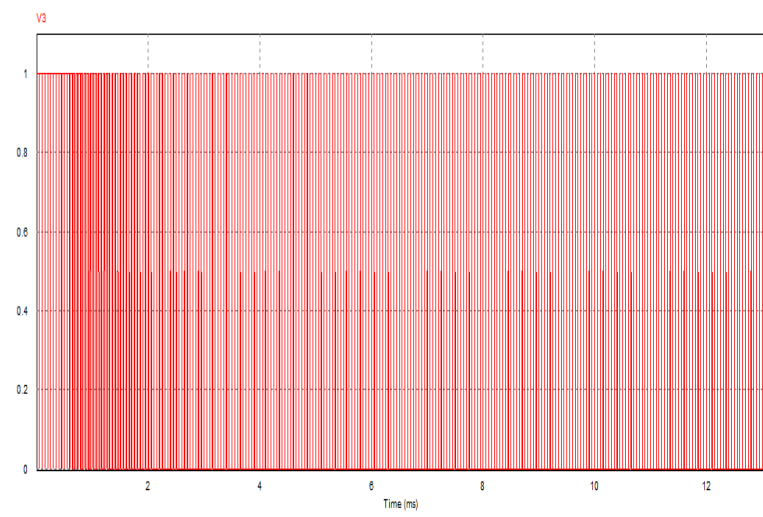

FIGURE VI. STARTING STAGE

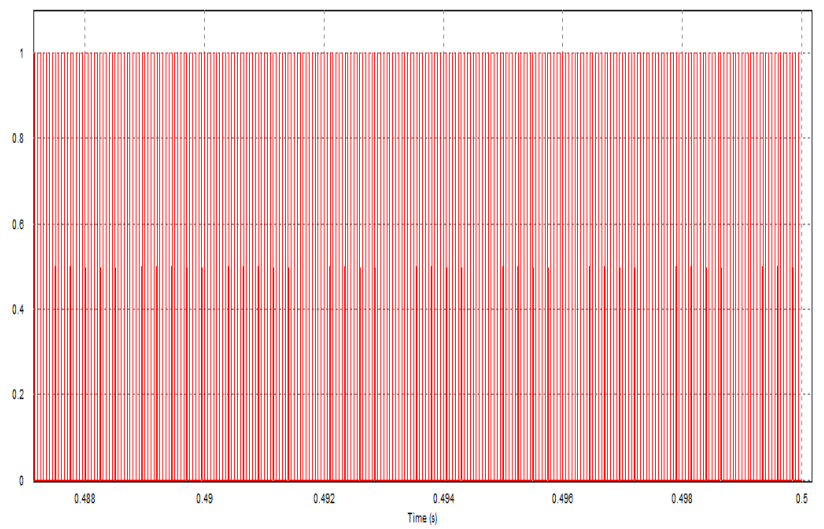

FIGURE VII. STABLE STAGE

\section{B. Simulation of Independent Control Multiple Parallel Current Source Modules}

Corresponding to Fig. 2, the current output of the independent control multiple parallel current sources is simulated, and the simulation circuit is shown in Fig. 8.

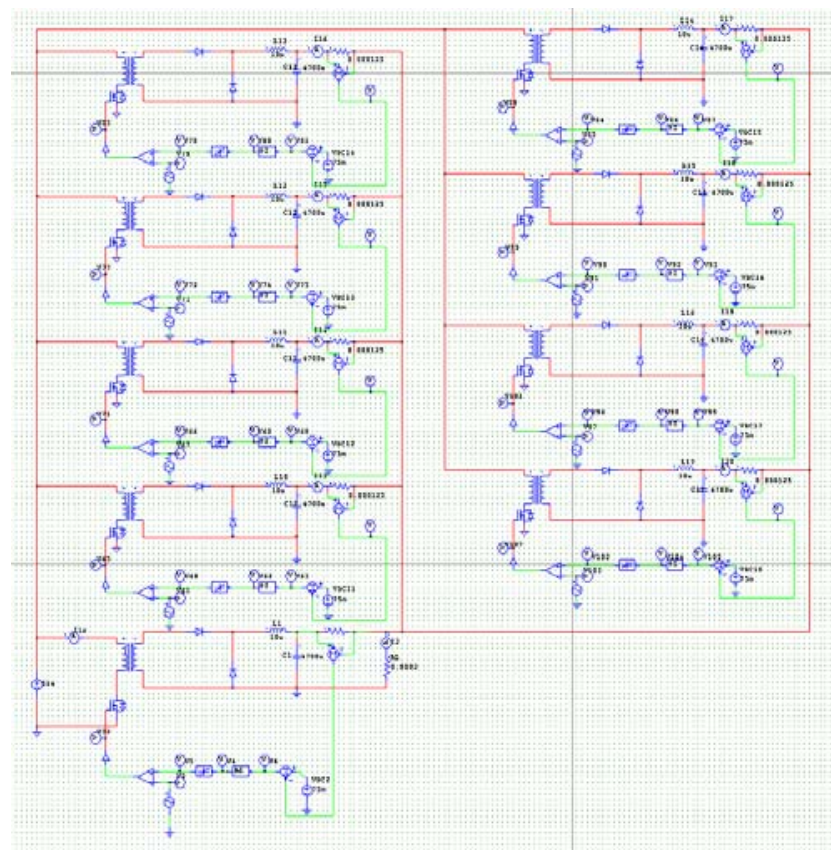

FIGURE VIII. SIMULATION CIRCUIT DIAGRAM

The current output simulation result are shown in Figure 9. As can be seen from the figure, the current output is 5400A, and its fluctuation coefficient is larger than that of the $600 \mathrm{~A}$ current source module, and the stabilization time is about $0.2 \mathrm{~s}$, which can meet the requirements. 


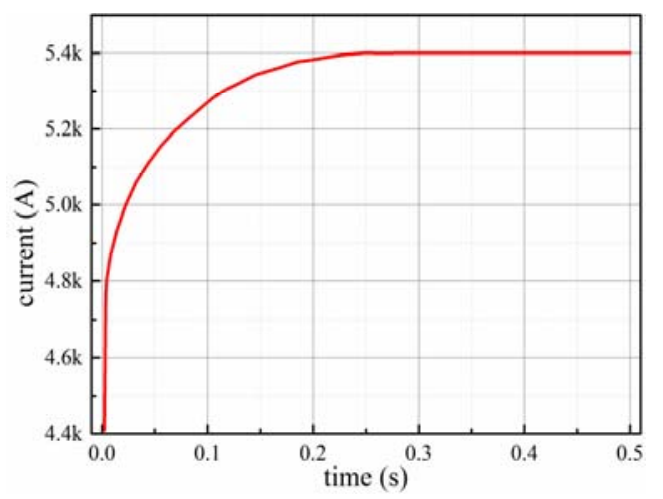

FIGURE IX. SIMULATION RESULT

\section{Simulation of Unified Control Multiple Parallel Current} Source Module

Corresponding to Fig. 3, the current output of the unified control multiple parallel current sources is simulated, and the simulation circuit is shown in Fig. 10.

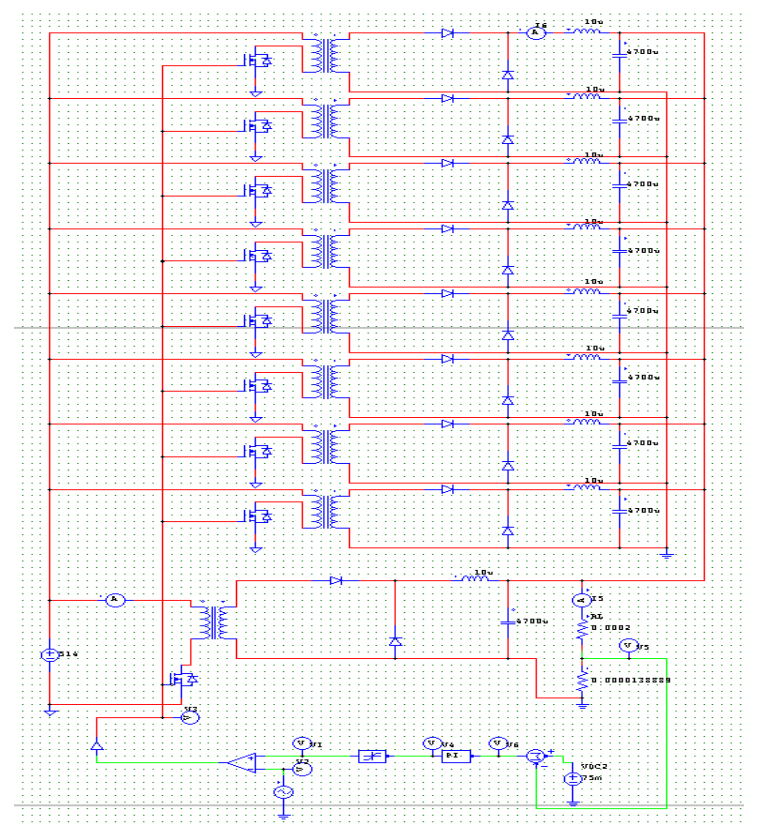

FIGURE X. SIMULATION CIRCUIT DIAGRAM

The current output simulation result are shown in Fig. 11. As can be seen from the figure, the current output is $5400 \mathrm{~A}$, and the result is similar to the independent control.

In the actual circuit, the unified control method needs to further consider the circulation problem between multiple channels. The circulation generated between the branches will affect the life of the device. In general, resistance can be added to each branch to solve the circulation problem. However, due to the large current of each branch of the system designed in this paper, it will seriously affect the power supply requirements. Therefore, it is determined to choose the independent control multiple parallel scheme as the main circuit topology of the DC calibration current source.

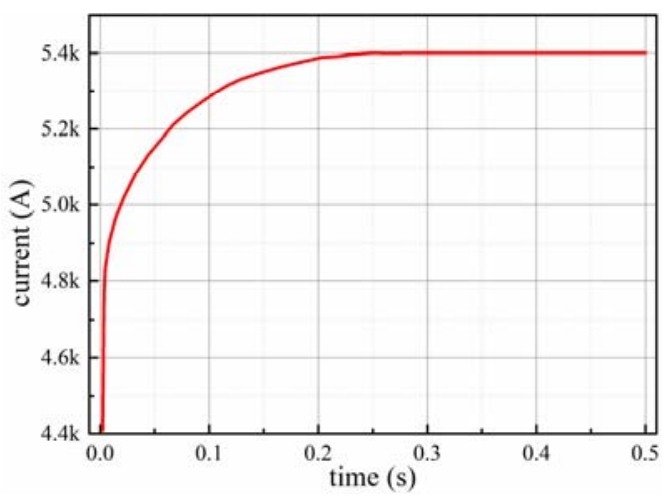

FIGURE XI. SIMULATION RESULT

\section{CONCLUSION}

In this paper, the technical indicators and design requirements of calibration current source for DC current transformer are analyzed theoretically. Based on the structural design of various technical solutions and the applicable power range, the theoretical overall design and simulation of the circuit topology of high-current DC current generating devices are performed. By comparing and analyzing the simulation results, it is determined to choose the independent control multiple parallel scheme as the main circuit topology of the DC calibration current source.

\section{REFERENCES}

[1] A. Hebra, "The reality of generation and distribution of electric power, Part 2: the other face of ultrahigh voltage power transmission," Instrumentation \& Measurement Magazine, IEEE, vol. 15, pp. 22-30, May 2012.

[2] Z. Y. Liu, X. H. Qin, L. Zhao and Q. B. Zhao, "Study on the application of UHVDC hierarchical connection mode to multi-infeed HVDC system," Proceedings of the CSEE, vol. 33, pp. 1-10, April 2013.

[3] Z. Y. Liu, Y. B. Shu, W. L. Zhang and Y. Z. Zhang, "Study on voltage class series for HVDC transmission system," Proceedings of the CSEE, vol. 28, pp. 1-8, April 2008.

[4] W. Yang, J. L. Yang, Y. J. Hou and D. S. Zhang, "Development of \pm 800 kV DC electronic current transformer," High Voltage Apparatus, vol. 47, pp. 10-17, January 2011.

[5] X. Q. Wang, B. L. Jiao and X. Li, "Design of $500 \mathrm{kV}$ direct current transformer insulated by $\mathrm{SF}_{6}$," High Voltage Engineering, vol. 35, pp. 379-383, February 2009.

[6] Y. Xu, Y. Zhang, M. J. Zhu, J. S. Wang and M. Y. Ye, "Air core coil based harmonic current measurement in HVDC and its performance analysis," Automation of Electric Power Systems, vol. 29, pp. 87-90, November 2005.

[7] Y. Xu, X. T. Han, X. Xiao, H. Rao and C. Fu, "Skin effect analysis of electronic current transformer in $\pm 500 \mathrm{kV}$," Transactions of China Electro technical Society, vol. 11, pp. 10-13, November 2008. 